\title{
Comparação de Sistemas de Avaliação de Dietas para Bovinos no Modelo de Produção Intensiva de Carne. II - Creep feeding ${ }^{1}$
}

\section{Rodolfo Marques de Brito ${ }^{2}$, Alexandre Amstalden Moraes Sampaio ${ }^{3}$, Geraldo Maria da Cruz ${ }^{4}$, Maurício Mello de Alencar ${ }^{4}$, Pedro Franklin Barbosa ${ }^{4}$, Rogério Taveira Barbosa ${ }^{4}$}

RESUMO - Foram utilizados 29 bezerros lactentes da raça Canchim com 55 dias de idade e peso corporal médio de $107 \mathrm{~kg}$, que receberam suplemento alimentar durante a estação chuvosa, visando avaliar o desempenho proporcionado pelos ajustes nutricionais recomendados por diferentes sistemas de avaliação de dietas. Os suplementos, à base de milho em grão moído, farelo de algodão e farelo de soja, seguiram as recomendações do Sistema de Proteína Metabolizável (MP), do Sistema de Proteína e Carboidratos Líquidos de Cornell (CNCPS) e do Sistema de Proteína Digestível no Intestino (PDI), para possibilitar o mais elevado ganho de peso corporal possível, conforme indicação de cada sistema de ajuste. O ganho diário de peso corporal não diferiu entre os tratamentos CNCPS, MP e PDI, com médias de 1,0 kg/cab. para cada um dos três tratamentos estudados. Foram estimadas as diferenças de peso corporal à desmama, em relação a um lote testemunha sem suplementação, para que o creep-feeding proporcionasse rentabilidades líquidas de $0 ; 0,6 ; 1,2$; e $6 \%$ ao mês, encontrando-se valores de 15,5;27,1; 17,1; e 15,9 para o CNCPS; 27,9; 17,6; 16,4; e 28,7 para o MP; e 18,1; 20,4; 35,6; e 22,5 em kg/cab. para o sistema PDI. Concluiu-se que os suplementos avaliados pelos sistemas proporcionaram resultados de desempenho animal compatíveis com os estimados.

Palavras-chave: bezerros, Brachiaria brizantha, conversão alimentar, desempenho

\section{Comparison of Diet Evaluation Systems for Cattle in an Intensive Beef Production Model. II - Creep-feeding}

\begin{abstract}
Twenty-nine suckling Canchim calves averaged $107 \mathrm{~kg}$ of body weight and 55 days of age were fed with supplement during the wet season, in order to evaluate the performance provided by nutritional adjustments recommended by different systems of evaluation of diets. Supplements were composed of grounded corn grain, cottonseed meal and soybean meal, in agreement with the recommendations of the Metabolizable Protein System (MP); Cornell Net Carbohydrate and Protein System (CNCPS); and Intestine Digestible Protein System (PDI), for the highest possible body weight gain, according to indications of each adjustment system. The daily body weight gain obtained did not differ among treatments CNCPS, MP and PDI, with mean of $1.0 \mathrm{~kg} / \mathrm{head}$ for each treatment studied. The body weight differences at weaning, in relation to a control group without supplementation were estimated, so that the creep-feeding would provide monthly net profit of $0,0.6,1.2$, and $6 \%$, and values of $15.5,27.1,17.1$, and 15.9 were observed for the CNCPS; 27.9 , 17.6, 16.4, and 28.7 for the MP; 18.1, 20.4, 35.6, and $22.5 \mathrm{~kg}$ body weight/head for the PDI system. It was concluded that the evaluated supplements provided results compatible with the estimated animal performance.
\end{abstract}

Key Words: Brachiaria brizantha, calves, feed conversion, performance

\section{Introdução}

A criação do bezerro, que em muitos casos dura cerca de 200 dias, é sempre motivo de especial atenção por parte do produtor de gado de corte, pois é nesta fase do sistema de produção que muitos fatores importantes começam a interferir no bom desenvolvimento do bezerro. Se a matriz foi bem alimentada no período de gestação, especialmente no pré-parto, deverá parir um produto saudável, e a partir daí, dar condições para o máximo desenvolvimento do bezerro pode não ser tarefa exclusiva da vaca e portanto, fornecer boas pastagens, minerais e suplementação adicional é fundamental para explorar ao máximo o potencial genético do animal.

Nesse contexto, a técnica de alimentação suplementar denominada creep-feeding pode assumir grande importância e, conforme as circunstâncias, tornar-se quesito indispensável para encurtar o tempo necessário ao acabamento dos animais para abate, além de 
proporcionar significativo descanso da matriz, o que resulta em melhoria das suas funções reprodutivas, pois alivia a carga produtiva a ela imposta. Por outro lado, a suplementação deve ser criteriosa e adequada às condições de produção de cada sistema, sendo necessária uma avaliação de cada dieta dentro dos modernos sistemas de nutrição, indicando se há equilíbrio entre os alimentos e se os requerimentos são atendidos, sem gastos desnecessários de nutrientes.

Taylor \& Field (1999) enumeraram como vantagens do creep-feeding: 1) maior peso corporal à desmama; 2) expressão do potencial genético em animais melhorados; 3) impulso na comercialização de animais de raças puras; 4) redução do estresse à desmama; 5) descanso da matriz. Por outro lado, os mesmos autores descreveram algumas desvantagens da suplementação para bezerros lactentes: 1) custo do ganho de peso adicional pode ser mais alto que a receita; 2) técnica delicada para aplicação em fêmeas de reposição; 3) pouca diferença de peso ao sobreano entre animais que receberam ou não o suplemento; 4) pouca ou nenhuma diferença de preço na comercialização pós-desmama de animais que receberam ou não o suplemento.

Pacola et al. (1977) estudaram o efeito de alimentação suplementar para bezerros em aleitamento sobre o peso à desmama e pós-desmama, quando então as fêmeas ficaram em pastejo até 20 meses, e os machos até 15 meses, sendo então confinados por 120 dias. Durante o aleitamento, o lote que recebeu suplemento consumiu $1,15 \mathrm{~kg}$ suplemento/cab./dia (concentrado com $80 \%$ de milho desintegrado com palha e sabugo $+20 \%$ de torta de algodão). Até os quatro meses de idade, não houve diferença entre lotes que receberam suplemento e lotes-controle, mas aos sete meses, os animais do lote que consumiu suplemento estavam $27,1 \mathrm{~kg} / \mathrm{cab}$. mais pesados. O mesmo foi observado aos 15 meses, quando os animais que receberam alimento suplementar estavam $22 \mathrm{~kg} / \mathrm{cab}$. mais pesados que as testemunhas. Aos 20 meses, a vantagem das fêmeas com alimentação adicional sobre as testemunhas foi de $17 \mathrm{~kg} / \mathrm{cab}$., e a vantagem dos machos, de 31,6 kg/cab., após o confinamento de 120 dias. Após o confinamento, $56 \%$ dos machos de creep-feeding alcançaram o peso corporal de $430 \mathrm{~kg}$, o que foi observado em apenas $12 \%$ dos machos-controle.

Em outro trabalho, Pacola et al. (1989) utilizaram 495 bezerros da raça Nelore, nascidos de 1983 a 1986, divididos em dois lotes: creep-feeding x controle

R. Bras. Zootec., v.31, n.2, p.1002-1010, 2002 (suplemento) (sem creep-feeding). A dieta foi composta de $80 \%$ de milho e $20 \%$ de farelo de algodão, registrando-se o consumo médio de $0,328 \mathrm{~kg} / \mathrm{cab}$./dia. Aos quatro e sete meses de idade, houve superioridade do lote que recebeu suplemento em 5,6 e $13 \mathrm{~kg} / \mathrm{cab}$., acompanhada de redução na mortalidade de 3 para $1,28 \%$. Os bezerros filhos de primíparas e de vacas velhas foram os que mais se beneficiaram da suplementação, e, de modo geral, as vacas com bezerros que consumiram suplemento apresentaram maior eficiência reprodutiva e maior ganho de peso durante o aleitamento.

No trabalho que deu continuidade ao anterior, Pacola et al. (1991) avaliaram o efeito da suplementação no desempenho pós-desmama dos animais e registraram uma perda de peso de $9 \mathrm{~kg} / \mathrm{cab}$. imediatamente após a desmama. Os animais foram confinados, e aos 383 dias de idade observou-se uma vantagem de $7,4 \mathrm{~kg} / \mathrm{cab}$. para o lote que recebeu suplemento. Após o confinamento, os animais foram levados ao pasto por um período de 167 dias, e não se observou diferença entre os animais-controle e aqueles que consumiram suplemento. Concluiu-se que a influência da suplementação sobre os pesos pós-desmama persistiu até a idade de 18 meses, embora tenha diminuído de $13,2 \mathrm{~kg} / \mathrm{cab}$ aos 210 dias para $7,4 \mathrm{~kg} / \mathrm{cab}$. aos 383 dias.

Nesta mesma linha de investigação, Martin et al. (1981), trabalhando com machos Aberdeen-Angus, confinados pós-desmama até 365 dias de idade, verificaram que os bezerros com alimentação adicional no aleitamento mantiveram a vantagem observada à desmama, mesmo com uma redução no diferencial de $2 \mathrm{~kg} / \mathrm{cab}$. Curiosamente, no caso das fêmeas que foram alimentadas para ganhos de $0,5 \mathrm{~kg} / \mathrm{cab} . / \mathrm{dia}$ pós-desmama, os animais de creep-feeding, que apresentavam uma superioridade de $10 \mathrm{~kg} / \mathrm{cab}$ à desmama, foram ultrapassados pelas testemunhas em $7 \mathrm{~kg} / \mathrm{cab}$. aos 365 dias de idade.

Pacola et al. (1993) avaliaram o efeito da suplementação alimentar nas fases pré- e pós-desmama, em fêmeas zebuínas da raça Nelore, sobre os pesos e ganhos aos 210, 390 e 550 dias de idade, constituindo quatro lotes experimentais: 1) suplementação pré- e pós-desmama; 2) suplementação pré-desmama; 3) suplementação pós-desmama; e 4) sem suplementação. O concentrado do creep-feeding foi composto de $80 \%$ de milho e $20 \%$ de farelo de algodão, registrando-se o consumo médio de $0,328 \mathrm{~kg} / \mathrm{cab} . / \mathrm{dia}$. Na fase pós-desmama, os animais receberam diariamente $9,9 \mathrm{~kg}$ de silagem de milho e 
$0,69 \mathrm{~kg}$ de farelo de algodão por cabeça. As fêmeas com suplementação pré- e pós-desmama e as fêmeas com suplementação pré-desmama foram superiores às demais aos 210 dias (13,7 kg/cab.), 390 dias (11,4 $\mathrm{kg} / \mathrm{cab}$.) e 550 dias $(9,7 \mathrm{~kg} / \mathrm{cab}$.). Os animais que receberam suplemento pré- e pós-desmama foram superiores aos que não receberam aos 390 e 550 dias em 45,9 e 23,6 kg/cab. respectivamente, e os animais que consumiram suplemento após a desmama foram superiores aos testemunhas aos 390 e 550 dias em 30,4 e $10,2 \mathrm{~kg} / \mathrm{cab}$., respectivamente.

Lusby (1995) estudou os benefícios de adoção da técnica do creep-feeding sob o complexo ponto de vista das prioridades do bezerro lactente quanto à ingestão de nutrientes e sugeriu que um eficiente programa de suplementação deve adicionar nutrientes à dieta do bezerro e não substituir nutrientes que naturalmente estariam presentes no leite e na forragem ingeridos. Sob esta ótica, o autor explicou que a utilização de suplementos com consumo limitado pode tornar o creep-feeding uma técnica economicamente viável, com o objetivo de corrigir deficiências nutricionais e manter elevada a ingestão de forragem pelo animal. $O$ autor avaliou o efeito de suplementação em três lotes: suplemento limitado; suplemento ad libitum; e sem suplemento. Os animais com suplementação à vontade foram os mais pesados à desmama, porém apresentaram conversão alimentar de $7,8 \mathrm{~kg}$ por unidade de peso corporal adicionada com o suplemento, enquanto o lote com consumo restringido apresentou conversão de $3,3: 1$, indicando que, no tratamento ad libitum, houve substituição de nutrientes, e não suplementação de nutrientes. O lote restringido chegou à desmama 13,6 kg/cab. mais pesado que o lote testemunha.

Assim, o objetivo deste trabalho foi comparar e avaliar o desempenho de bezerros de corte, em pastagem de capim Marandu (Brachiaria brizantha), durante a estação chuvosa, suplementada segundo as recomendações de diferentes sistemas de avaliação de dietas.

\section{Material e Métodos}

O trabalho foi conduzido no Setor de Bovinocultura de Corte da FCAV-Unesp/Jaboticabal, em área de 9 ha de pastejo rotativo intensivo de capim-Marandu, que recebeu aplicação de $130 \mathrm{~kg} \mathrm{~N} / \mathrm{ha}$, parcelados em quatro aplicações, na estação chuvosa. A área foi dividida em três subáreas experimentais ( 3 ha cada) manejadas num esquema de rodízio com seis dias de ocupação e 42 dias de descanso. Cada subárea de pastejo rotativo foi equipada com um módulo de alimentação seletiva, em ferro galvanizado, instalado na área de descanso dos animais, para viabilizar o arraçoamento seletivo dos bezerros (creep-feeding), de tal modo que as matrizes ficassem impedidas de alcançar o cocho de alimentação, e os bezerros tivessem livre acesso ao mesmo. Cada módulo de alimentação seletiva, que mediu $5 \times 5 \mathrm{~m}$, foi dotado de regulagem lateral nas barras verticais e horizontais e abrigou um cocho com capacidade para alimentação simultânea de 10 animais.

Essa regulagem permitiu um ajuste fino da distância entre as barras verticais, que possibilitou aumento do vão livre à medida que os bezerros aumentaram seu tamanho corporal. O módulo de alimentação seletiva foi estrategicamente colocado próximo aos bebedouros e aos cochos de suplementação e mineralização das matrizes.

Foram utilizados 29 bezerros da raça Canchim, divididos em três lotes experimentais, que a partir de 40 dias de idade começaram a receber uma pequena quantidade de fubá de milho (50 g cab./dia), para que se acostumassem à alimentação dentro do módulo de arraçoamento seletivo. Quando os lotes atingiram em média 55 dias de idade, os animais foram pesados e iniciou-se o fornecimento do suplemento específico para cada tratamento, de acordo com as recomendações de cada um dos três sistemas: CNCPS (Fox et al., 1992), MP (AFRC, 1993) e PDI (Jarrige, 1990). A idade de suplementação para bezerros a partir de 60 dias foi reportada por Pacola et al. (1977; 1989; 1991; 1993), em razão do consumo extremamente baixo registrado antes dessa idade. Além disso, os próprios autores do sistema CNCPS não recomendam sua utilização para animais abaixo de dois meses de idade. Os autores do sistema PDI também recomendam que a suplementação seja feita apenas depois de decorridas "algumas" semanas de idade. Dessa forma, o experimento foi estruturado em quatro períodos de 35 dias (com pesagem dos animais ao final/início de cada período), até a idade de 195 dias (6,5 meses de idade), quando os animais foram desmamados, seguindo-se então a pesagem final. Os suplementos foram compostos por milho em grão moído, farelo de soja e farelo de algodão, e o alimento foi fornecido, à vontade, diariamente às $10 \mathrm{~h}$. As sobras de alimento do cocho foram quantificadas duas vezes por semana, a fim de estimar a ingestão do concentrado pelos 
animais. Em razão do período experimental situar-se na estação chuvosa, o recolhimento e a quantificação das sobras também foram realizados nos dias em que houve umedecimento do concentrado como resultado de chuvas de forte intensidade, que não foram contidas pelas coberturas de proteção do cocho instaladas em cada módulo de alimentação seletiva.

Os ingredientes do concentrado foram amostrados diretamente da sacaria, sendo as amostras encaminhadas ao laboratório para serem analisadas. As análises referentes à composição média dos ingredientes, nos teores de matéria seca e proteína bruta, basearam-se nos métodos descritos pela AOAC (1995). As fórmulas das rações utilizadas no presente estudo estão apresentadas na Tabela 1 .

A mistura dos ingredientes componentes de cada dieta foi feita em misturador horizontal com capacidade para $500 \mathrm{~kg}$ e dupla rosca helicoidal, durante 12 minutos. A formulação das dietas nos tratamentos MP e PDI seguiu o balanceamento por custo minimizado, sem prescindir das recomendações e dos princípios de alimentação preconizados pelos sistemas para o máximo ganho diário de peso corporal, considerando a ingestão de pastagem de no máximo
$2,5 \%$ do peso corporal em matéria seca. O animal padrão definido no modelo de ajuste e formulação foi a fêmea cruzada, com precocidade e estrutura corporal médias. No caso do CNCPS, não houve formulação por custo minimizado, porém buscou-se atender ao máximo de requisitos para que a ração guardasse as características do sistema de ajuste. Isso explica o fato das dietas experimentais não possuírem todos os alimentos em suas fórmulas finais. Ao final do segundo período experimental, após a pesagem de cada lote, as dietas foram reajustadas, e a nova formulação permaneceu até o término do período experimental. Procurou-se, assim, acompanhar e atender às exigências de crescimento e desenvolvimento dos animais.

A distribuição dos animais nos tratamentos seguiu o modelo do delineamento inteiramente casualizado com três tratamentos e dez, dez e nove repetições, para os tratamentos CNCPS, PDI e MP, respectivamente. As médias de peso corporal inicial e ganho de peso corporal foram comparadas pelo teste de Tukey (Banzatto \& Kronka, 1992), por meio de contrastes ortogonais no nível de $5 \%$ de probabilidade. Efetuou-se ainda uma análise econômica da

Tabela 1 - Proporção dos ingredientes no concentrado (\%) para suplementação da pastagem para bezerros da raça Canchim lactentes de 55 a 125 dias de idade (períodos $1+2$ ) e 126 a 195 dias de idade (períodos $3+4$ ) Table 1 - Proportion of ingredients in concentrate (\%) for pasture supplementation of suckling Canchim calves in 55 to 125 days of age (periods $1+2$ ) and 126 to 195 days of age (periods $3+4$ )

\begin{tabular}{|c|c|c|c|c|c|c|}
\hline \multirow[b]{3}{*}{$\begin{array}{l}\text { Ingredientes } \\
\text { Ingredients }\end{array}$} & \multicolumn{6}{|c|}{$\begin{array}{c}\text { Tratamentos } \\
\text { Treatments } \\
\end{array}$} \\
\hline & \multicolumn{2}{|c|}{ CNCPS } & \multicolumn{2}{|c|}{ MP } & \multicolumn{2}{|c|}{ PDI } \\
\hline & $\begin{array}{c}\text { Períodos } \\
1 \text { e } 2 \\
\text { Periods } \\
1 \text { and } 2 \\
\end{array}$ & $\begin{array}{c}\text { Períodos } \\
3 \text { e } 4 \\
\text { Periods } \\
1 \text { and } 2 \\
\end{array}$ & $\begin{array}{c}\text { Períodos } \\
1 \text { e } 2 \\
\text { Periods } \\
1 \text { and } 2\end{array}$ & $\begin{array}{c}\text { Períodos } \\
3 \text { e } 4 \\
\text { Periods } \\
1 \text { and } 2 \\
\end{array}$ & $\begin{array}{c}\text { Períodos } \\
1 \text { e } 2 \\
\text { Periods } \\
1 \text { and } 2 \\
\end{array}$ & $\begin{array}{c}\text { Períodos } \\
3 \text { e } 4 \\
\text { Periods } \\
1 \text { and } 2 \\
\end{array}$ \\
\hline $\begin{array}{l}\text { Fubá de milho } \\
\text { Corn meal }\end{array}$ & 52,9 & 73,8 & 28,1 & 19,9 & 72,7 & 72,7 \\
\hline $\begin{array}{l}\text { Farelo de soja } \\
\text { Soybean meal }\end{array}$ & 11,8 & 12,1 & 61,5 & 70,5 & - & - \\
\hline $\begin{array}{l}\text { Farelo de algodão } \\
\text { Cottonseed meal }\end{array}$ & 35,3 & 14,1 & 10,4 & 9,6 & 27,3 & 27,3 \\
\hline $\begin{array}{l}\text { Total } \\
\text { Total }\end{array}$ & 100,0 & 100,0 & 100,0 & 100,0 & 100,0 & 100,0 \\
\hline $\begin{array}{l}\text { MS (\% suplemento) } \\
\text { DM (\% supplement) }\end{array}$ & 88,0 & 88,0 & 89,0 & 89,0 & 88,0 & 88,0 \\
\hline $\begin{array}{l}\mathrm{PB}(\% \mathrm{MS}) \\
C P(\% \mathrm{DM})\end{array}$ & 26,2 & 19,5 & 38,0 & 41,3 & 18,9 & 18,9 \\
\hline $\begin{array}{l}\mathrm{R} \$ / \mathrm{kg} \text { suplemento }{ }^{2} \\
R \$ / \mathrm{kg} \text { supplement }\end{array}$ & 0,223 & 0,192 & 0,302 & 0,322 & 0,184 & 0,184 \\
\hline
\end{tabular}

R. Bras. Zootec., v.31, n.2, p.1002-1010, 2002 (suplemento) 
adoção da técnica de suplementação da pastagem de bezerros lactentes, considerando-se o preço dos ingredientes dos suplementos e o preço de venda dos animais fornecidos por boletins informativos do setor de pecuária de corte à época da realização do trabalho.

\section{Resultados e Discussão}

Os resultados de consumo do suplemento em cada um dos períodos experimentais e também a média do período total estão apresentados na Tabela 2. É possível observar que no 1o período, o consumo de suplemento pelos bezerros foi reduzido, situando-se em torno de $75 \mathrm{~g} / \mathrm{cab}$./dia. À medida que os animais se desenvolveram, o consumo aumentou rapidamente, variando entre os tratamentos.

Durante a maior parte do período experimental, o tratamento PDI proporcionou maior ingestão de matéria seca de suplemento, sendo superado pelos demais no período final. Entre os tratamentos MP e CNCPS, houve equilíbrio constante durante todo o ensaio, pois o primeiro manteve-se com média de ingestão superior ao segundo. No período total, o tratamento PDI proporcionou a maior ingestão absoluta de concentrado pelos bezerros $(0,73 \mathrm{~kg} / \mathrm{cab}$./dia), o que não ocorreu com a ingestão relativa, que foi maior no tratamento MP $(0,42 \%$ PC).

Os resultados de consumo de proteína em cada um dos períodos experimentais e também a média do período total estão apresentados na Tabela 3. É possível observar que no 1o período o consumo de proteína pelos bezerros foi reduzido, situando-se em torno de $25 \mathrm{~g} / \mathrm{cab}$./dia, como resultado direto da baixa ingestão de matéria seca. Nota-se, também, o elevado consumo de proteína em relação ao peso corporal no caso do tratamento MP, quando comparado aos demais, também como conseqüência deste tratamento ter apresentado o maior consumo de matéria seca em relação ao peso corporal.

Embora as recomendações dos sistemas de formulação tenham sido respeitadas, é possível notar o elevado teor protéico do suplemento recomendado pelo sistema MP, em ambas as fórmulas (inicial e final), enquanto os sistemas CNCPS e PDI recomendaram suplementos de concentração protéica na matéria seca, em níveis mais próximos daqueles recomendados pelos trabalhos encontrados na literatura pesquisada e nos trabalhos de Pacola et al. (1977, 1989, 1991 e 1993).

Constam na Tabela 4 os resultados da análise estatística para o ganho de peso corporal médio dos bezerros e também o resultado do ganho de peso em cada período experimental.

É interessante notar a semelhança absoluta entre as médias dos tratamentos no período total e em ambos os períodos iniciais. Nos dois períodos finais, já foi possível notar diferenças no ganho de peso

Tabela 2 - Ingestão de suplemento (kg MS/cab./dia e \%PC) proporcionado pelos tratamentos avaliados em cada período e no período total

Table 2 - Supplement intake (kg DM/head/day and \%BW) proportioned by the evaluated treatments in each period and in overall period

\begin{tabular}{|c|c|c|c|c|c|c|}
\hline \multirow[b]{3}{*}{$\begin{array}{l}\text { Período } \\
\text { Period } \\
\end{array}$} & \multicolumn{6}{|c|}{$\begin{array}{c}\text { Tratamentos } \\
\text { Treatments } \\
\end{array}$} \\
\hline & \multicolumn{2}{|c|}{ CNCPS } & \multicolumn{2}{|c|}{ MP } & \multicolumn{2}{|c|}{ PDI } \\
\hline & $\begin{array}{l}\mathrm{kg} \mathrm{MS} \\
\mathrm{kg} D M\end{array}$ & $\begin{array}{l}\% \mathrm{PC} \\
\% B W\end{array}$ & $\begin{array}{l}\mathrm{kg} \mathrm{MS} \\
\mathrm{kg} D M\end{array}$ & $\begin{array}{l}\% \mathrm{PC} \\
\% B W\end{array}$ & $\begin{array}{l}\mathrm{kg} \mathrm{MS} \\
\mathrm{kg} D M\end{array}$ & $\begin{array}{l}\% \mathrm{PC} \\
\% B W\end{array}$ \\
\hline $\begin{array}{l}1 \underline{\mathrm{o}}(1-35 \text { dias }) \\
1^{\text {st }}(1-35 \text { days })\end{array}$ & 0,07 & 0,05 & 0,08 & 0,07 & 0,08 & 0,06 \\
\hline $\begin{array}{l}2^{\underline{o}}(36-70 \text { dias }) \\
2^{\text {nd }}(36-70 \text { days })\end{array}$ & 0,24 & 0,15 & 0,34 & 0,23 & 0,42 & 0,25 \\
\hline $\begin{array}{l}3 \underline{\text { o }}(71-105 \text { dias }) \\
3^{r d}(71-105 \text { days })\end{array}$ & 0,68 & 0,34 & 0,80 & 0,44 & 1,00 & 0,48 \\
\hline $\begin{array}{l}4^{\mathrm{o}}(106-140 \text { dias }) \\
4^{\text {th }}(106-140 \text { days })\end{array}$ & 1,45 & 0,62 & 1,55 & 0,72 & 1,40 & 0,58 \\
\hline $\begin{array}{l}\text { Total (1 - } 140 \text { dias }) \\
\text { Overall }(1-140 \text { davs }\end{array}$ & 0,61 & 0,33 & 0,69 & 0,42 & 0,73 & 0,39 \\
\hline
\end{tabular}

${ }^{1}$ CNCPS - Sistema de proteína e carboidratos líquidos de Cornell; MP - Sistema de Proteína Metabolizável; PDI - Sistema de Proteína Digestível no Intestino.

CNCPS - Cornell Net Carbohydrate and Protein System; MP - Metabolizable Protein System; PDI - Intestine Digestible Protein System.

\section{R. Bras. Zootec., v.31, n.2, p.1002-1010, 2002 (suplemento)}


Tabela 3 - Ingestão de proteína bruta do suplemento (kg PB/cab./dia e \%PC) proporcionado pelos tratamentos avaliados em cada período e no período total

Table 3 - Protein supplement intake $(\mathrm{kg} \mathrm{CP} / \mathrm{head} / \mathrm{day}$ and \%BW) proportioned by evaluated treatments in each period and in overall period

\begin{tabular}{|c|c|c|c|c|c|c|}
\hline \multirow{4}{*}{$\begin{array}{l}\text { Período } \\
\text { Period }\end{array}$} & \multicolumn{6}{|c|}{$\begin{array}{l}\text { Tratamentos }^{1} \\
\text { Treatments }\end{array}$} \\
\hline & \multicolumn{2}{|c|}{ CNCPS } & \multicolumn{2}{|c|}{ MP } & \multicolumn{2}{|c|}{ PDI } \\
\hline & $\mathrm{kg}$ PB & $\% \mathrm{PC}$ & $\mathrm{kg} P B$ & $\% \mathrm{PC}$ & $\mathrm{kg} P B$ & $\% \mathrm{PC}$ \\
\hline & $\mathrm{kgCP}$ & $\% B W$ & $\mathrm{kgCP}$ & $\% B W$ & $\mathrm{kgCP}$ & $\% B W$ \\
\hline $1 \underline{0}(1-35$ dias $)$ & 0,02 & 0,01 & 0,03 & 0,03 & 0,02 & 0,01 \\
\hline $1^{s t}(1-35$ days $)$ & & & & & & \\
\hline $\begin{array}{l}2^{\mathrm{o}}(36-70 \text { dias }) \\
2^{\text {nd }}(36-70 \text { days })\end{array}$ & 0,06 & 0,04 & 0,13 & 0,09 & 0,08 & 0,05 \\
\hline $\begin{array}{l}30 \text { ( }(71-105 \text { dias }) \\
3^{\text {rd }}(71-105 \text { days })\end{array}$ & 0,13 & 0,07 & 0,33 & 0,18 & 0,19 & 0,09 \\
\hline $\begin{array}{l}40(106-140 \text { dias }) \\
4^{\text {th }}(106-140 \text { days })\end{array}$ & 0,28 & 0,12 & 0,64 & 0,30 & 0,26 & 0,11 \\
\hline $\begin{array}{l}\text { Total ( } 1 \text { - } 140 \text { dias }) \\
\text { Overall ( } 1 \text { - } 140 \text { days })\end{array}$ & 0,12 & 0,07 & 0,28 & 0,17 & 0,14 & 0,07 \\
\hline
\end{tabular}

${ }^{1}$ CNCPS - Sistema de proteína e carboidratos líquidos de Cornell; MP - Sistema de Proteína Metabolizável; PDI - Sistema de Proteína Digestível no Intestino

CNCPS - Cornell Net Carbohydrate and Protein System; MP - Metabolizable Protein System; PDI - Intestine Digestible Protein System.

entre os tratamentos, com redução das médias nos tratamentos CNCPS e PDI e aumento na média do tratamento MP. Nos três tratamentos, a média final de ganho de peso corporal de todo o período experimental indicou que os bezerros provavelmente estiveram próximos do seu potencial genético para crescimento, o que também é reforçado pelo que foi observado nos ganhos de peso iniciais.

A semelhança observada nas médias de ganho de peso, em relação às marcantes diferenças nas dietas, especialmente em relação ao teor protéico, pode residir no fato de que há um limite físiológico para as taxas de ganho que os bezerros podem alcançar (Lusby, 1995). Se os bezerros têm acesso a elevadas quantidades de leite e forragem de boa qualidade, os animais ganham tanto quanto a sua habilidade genética lhes permitir. Esse pode ter sido o caso do presente estudo, pois o manejo em pastejo rotativo com adubação intensiva propiciou boa forragem, e em adição, as vacas vieram de um longo período de suplementação pré-parto, o que resultou em boa condição corporal e provavelmente em pequena limitação nutricional à produção leiteira na metade inicial da lactação. A reduzida efetividade do creep-feeding em aumentar os ganhos dos bezerros nessa condição pode resultar na substituição da forragem pelo suplemento, tornando inadequada a conversão alimentar, pois, em geral, as conversões mais eficientes do creep-feeding em peso adicional são obtidas quando os bezerros não atingem o seu potencial de crescimento alimentando-se exclusivamente de forragem e leite.

As diferenças obtidas nos períodos finais podem ser devidas à redução no aporte nutricional lácteo e também da qualidade e disponibilidade da forragem, que devido à aproximação do período seco declinou de valores estimados de $3.000 \mathrm{~kg} \mathrm{MS} / \mathrm{ha}$ para valores próximos a $1.500 \mathrm{~kg} \mathrm{MS} / \mathrm{ha}$. Considerando-se que os teores energéticos dos suplementos estiveram próximos entre os diferentes tratamentos, é possível que o maior aporte protéico do tratamento MP tenha garantido uma pequena elevação no ganho de peso do período final, ou seja, exatamente o oposto do que foi observado nos demais tratamentos, uma vez que esse nutriente é de grande importância no período inicial da vida do animal.

O decréscimo significativo no ganho de peso no período final dos tratamentos PDI e CNCPS, em contraste com o aumento do tratamento MP, sugeriu ainda que, nos períodos iniciais, os dois primeiros estivessem realizando de forma mais efetiva a suplementação da dieta do bezerro, enquanto o sistema MP estaria produzindo um efeito de substituição da dieta. Como o reajuste da dieta no tratamento MP propiciou aumento do teor protéico, a situação pode ter assumido uma característica diferente nos períodos 
Tabela 4 - Peso corporal inicial (PCl - kg) e ganhos de peso corporal (GPC - kg/cab./dia) total e em cada período e seus respectivos coeficientes de variação (cv)

Table 4 - Initial body weight (IBW - $\mathrm{kg}$ ) and body weight gain (BWG - kg/head/day) total and in each period and the respective variation coefficient (cv)

\begin{tabular}{|c|c|c|c|c|}
\hline \multirow[b]{2}{*}{$\begin{array}{l}\text { Variável }^{2} \\
\text { Variable }\end{array}$} & \multicolumn{4}{|c|}{$\begin{array}{c}\text { Tratamentos }^{1} \\
\text { Treatments }\end{array}$} \\
\hline & CNCPS & MP & PDI & $\mathrm{CV}(\%)$ \\
\hline $\begin{array}{l}\mathrm{PCI} \\
I B W\end{array}$ & 110,3 & 95,8 & 113,6 & 30,1 \\
\hline $\begin{array}{l}\text { GPC } 1 \text { o período }(1-35 \text { dias }) \\
B W G 1^{\text {st }} \text { period }(1-35 \text { days })\end{array}$ & 1,0 & 1,0 & 1,0 & 12,8 \\
\hline $\begin{array}{l}\text { GPC } 2^{\circ} \text { período }(36-70 \text { dias }) \\
B W G 2^{\text {nd }} \text { period }(36-70 \text { days })\end{array}$ & 1,1 & 1,0 & 1,1 & 16,5 \\
\hline $\begin{array}{l}\text { GPC } 3 \text { o período }(71-105 \text { dias }) \\
B W G 3^{\text {rd }} \text { period }(71-105 \text { days })\end{array}$ & $1,0^{\mathrm{ab}}$ & $0,9^{b}$ & $1,1^{\mathrm{a}}$ & 17,1 \\
\hline $\begin{array}{l}\text { GPC } 4^{\circ} \text { período }(106-140 \text { dias }) \\
B W G 4^{\text {th }} \text { period }(106-140 \text { days })\end{array}$ & $0,9^{a b}$ & $1,1^{\mathrm{a}}$ & $0,8^{\mathrm{b}}$ & 21,5 \\
\hline $\begin{array}{l}\text { GPC período total }(1-140 \text { dias }) \\
B W G \text { overall period }(1-140 \text { days })\end{array}$ & 1,0 & 1,0 & 1,0 & 12,3 \\
\hline $\begin{array}{l}\text { Peso corporal final }(\mathrm{kg})^{3} \\
\text { Final body weight }(\mathrm{kg})\end{array}$ & 250,3 & 235,8 & 253,6 & \\
\hline $\begin{array}{l}\text { Pesocorporal final (@) } \\
\text { Finalbodyweight (@) }\end{array}$ & 8,7 & 8,2 & 8,8 & \\
\hline $\begin{array}{l}{ }^{1} \text { CNCPS - Sistema de proteína e car } \\
\text { Proteína Digestível no Intestino. } \\
2 \text { Médias seguidas de letras diferent } \\
{ }^{3} \text { Rendimento de carcaça estimado } \\
{ }^{1} \text { CNCPS - Cornell Net Carbohydrate and } \\
{ }_{2}^{2} \text { Means followed by different letters in th }\end{array}$ & $\begin{array}{l}\text { uidos de } \mathrm{Cc} \\
\text { s diferem e } \\
\text { m; MP-Met } \\
\text { by Tukey tes }\end{array}$ & $\begin{array}{l}\text { Sistema } \\
\text { teste d } \\
\text { otein Sys }\end{array}$ & etabolizá & $\begin{array}{l}\text { Sistema de } \\
\text { ystem. }\end{array}$ \\
\hline
\end{tabular}

finais: o tratamento MP passou a suplementar o alimento naturalmente disponível aos animais, e os demais tratamentos não compensaram um pequeno déficit nutricional, resultando em pequena, porém significativa, diminuição do ganho de peso.

A adoção de qualquer prática de manejo e/ou alimentação deve ser analisada sob a ótica econômica. Embora o presente estudo não tenha contemplado a inclusão de um lote-controle sem suplementação, a questão que freqüentemente se apresenta é: qual é o custo do ganho adicional? Com efeito, é preciso preocupar-se com esse item, pois um eficiente programa de suplementação de forragem é aquele que resulta num grande aumento do ganho adicional por unidade de suplemento consumido. Muitos criadores e selecionadores de raças puras podem suplementar arbitrariamente a alimentação de seus bezerros porque o tamanho e a aparência desses animais são importantes para a comercialização. Já os criadores comerciais devem analisar o creep-feeding com base na avaliação de custos e retornos do incremento de peso dos bezerros à desmama.

\section{R. Bras. Zootec., v.31, n.2, p.1002-1010, 2002 (suplemento)}

Constam na Tabela 5 os dados de custo de alimentação de cada tratamento, bem como o diferencial necessário ( $\mathrm{kg}$ de bezerro ou $\mathrm{kg} / 100 \mathrm{~kg}$ de bezerro), por ocasião da desmama para que se obtivesse viabilidade econômica na adoção de cada ração em relação a um grupo de bezerros sem suplementação, segundo diferentes taxas de rentabilidade pretendidas. As taxas de rentabilidade foram escolhidas por representarem as opções de mercado ou investimentos que poderiam ser alternativas ao uso da técnica do creep-feeding: a) lucro zero - ponto em que o retorno proporcionado pelo ganho adicional do bezerro cobriria exatamente os custos de suplementação; b) $0,6 \%$ ao mês - representa a aplicação do capital na caderneta de poupança; c) $1,2 \%$ ao mês - fundos de renda fixa; e d) $6 \%$ ao mês - remuneração obtida no confinamento de bovinos de corte em anos favoráveis. O custo total de suplementação no período foi mais elevado no tratamento que adotou o sistema MP (R \$37,61/cab.). Esse fato deveu-se principalmente à associação de dois fatores: o custo mais elevado do suplemento recomendado por esse sistema (como fruto da maior 
Tabela 5 - Análise econômica do uso do creep-feeding conforme os tratamentos testados Table 5 - Economic analysis of use of creep-feeding, according to the evaluated treatments

\begin{tabular}{|c|c|c|c|}
\hline \multirow[b]{2}{*}{ Item $^{2}$} & \multicolumn{3}{|c|}{$\begin{array}{l}\text { Tratamentos } \\
\text { Treatments }\end{array}$} \\
\hline & CNCPS & MP & PDI \\
\hline Custo de suplementação ( $\mathrm{R} \$ / 140$ dias) & 19,01 & 34,75 & 21,22 \\
\hline \multicolumn{4}{|l|}{ Supplementation costs $(R \$ / 140$ days $)$} \\
\hline Outros custos no período ( $\mathrm{R} \$$ /cab.) & 2,00 & 2,00 & 2,00 \\
\hline \multicolumn{4}{|l|}{ Another costs in the period (R\$/head) } \\
\hline Remuneração do capital (6\% aa) & 0,49 & 0,86 & 0,54 \\
\hline \multicolumn{4}{|l|}{ Capital remuneration (6\%/year) } \\
\hline Total dos custos do creep-feeding ( $\mathrm{R} \$ / \mathrm{cab})$ & 21,50 & 37,61 & 23,76 \\
\hline $\begin{array}{l}\text { Total costs of creep-feeding }(R \$ / \mathrm{head}) \\
\text { Diferencial do creep-feeding para lucro zero ( } \mathrm{kg} / \mathrm{cab} .)\end{array}$ & 15,5 & 27,1 & 17,1 \\
\hline \multicolumn{4}{|l|}{ Creep-feeding differential for none net profit ( $k g / h e a d)$} \\
\hline $\begin{array}{l}\text { Diferencial do creep-feeding para lucro } 0,6 \% \text { a.m. }(\mathrm{kg} / \mathrm{cab}) \\
\text { Creep-feeding differential for } 0.6 \% / \text { month of net profit }(\mathrm{kg} / \mathrm{head})\end{array}$ & 15,9 & 27,9 & 17,6 \\
\hline \multicolumn{4}{|l|}{ Creep-feeding differential for $1.2 \% /$ month of net profit ( $\mathrm{kg} / \mathrm{head})$} \\
\hline $\begin{array}{l}\text { Diferencial do creep-feeding para lucro } 6,0 \% \text { a.m. }(\mathrm{kg} / \mathrm{cab}) \\
\text { Creep-feeding differential for } 6.0 \% / \text { month of net profit }(\mathrm{kg} / \mathrm{head})\end{array}$ & 20,4 & 35,6 & 22,5 \\
\hline \multicolumn{4}{|l|}{ Creep-feeding differential for none net profit $(\% B W)$} \\
\hline $\begin{array}{l}\text { Diferencial do creep-feeding para lucro } 0,6 \% \text { a.m. }(\% \mathrm{PC}) \\
\text { Creep-feeding differential for } 0.6 \% / \text { month of net profit }(\% B W)\end{array}$ & 6,4 & 11,8 & 6,9 \\
\hline Diferencial do creep-feeding para lucro $1,2 \%$ a.m. (\%PC) & 6,5 & 12,2 & 7,1 \\
\hline $\begin{array}{l}\text { Creep-feeding differential for } 1.2 \% / \text { month of net profit }(\% B W) \\
\text { Diferencial do creep-feeding para lucro } 6,0 \% \text { a.m. }(\% \mathrm{PC}) \\
\text { Creep-feeding differential for } 6.0 \% / \text { month of net profit }(\% B W)\end{array}$ & 8,1 & 15,1 & 8,9 \\
\hline \multicolumn{4}{|c|}{ 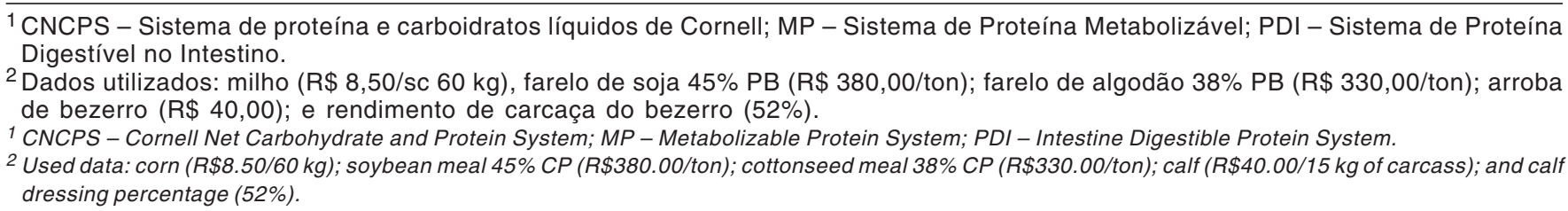 } \\
\hline
\end{tabular}

concentração protéica); e a maior ingestão de concentrado suplementar pelos bezerros.

$\mathrm{Na}$ prática, o diferencial obtido pelo lote que recebeu suplemento ajustado pelo MP em relação a um lote sem suplementação deveria ser de 27,1;27,9; 28,$7 ;$ e $35,6 \mathrm{~kg} / \mathrm{cab}$. à desmama para que se produzissem rentabilidades mensais de $0 ; 0,6 ; 1,2$; e $6 \%$, respectivamente. Esse diferencial é tanto mais difícil de obter à medida que se elevam os custos dos ingredientes do suplemento e/ou ocorre conversão alimentar inadequada no período chuvoso, quando os bezerros substituem forragem pelo suplemento.

$\mathrm{O}$ tratamento que se mostrou mais interessante foi o CNCPS, cuja lucratividade já começaria a aparecer em diferenciais de peso à desmama a partir de $15,5 \mathrm{~kg} / \mathrm{cab}$. ou $6,2 \%$ do peso corporal $(6,2 \mathrm{~kg}$ de bezerro a mais em $100 \mathrm{~kg}$ de bezerro desmamado). A obtenção de $8,1 \mathrm{~kg}$ a mais em cada $100 \mathrm{~kg}$ de bezerro desmamado que recebeu suplemento ajustado por esse sistema de nutrição proporcionaria a notável rentabilidade de $6 \%$ ao mês, cerca de dez vezes a da mais popular aplicação financeira do mercado - a caderneta de poupança. É importante notar ainda que a relação entre o peso adicionado pela suplementação e o lucro obtido mostrou-se linear nos diversos tratamentos testados. Isso mostra que o creep-feeding proporciona, a partir de um peso diferencial mínimo específico para cada sistema produtivo (mínimo econômico), rentabilidade fixa para cada unidade de peso adicional que se obtém pela suplementação da dieta dos bezerros. Pelo presente estudo, há evidências de que a exploração do potencial genético do bezerro (máximo genético), desde que este situe-se acima do mínimo econômico, é regida por incrementos de ganho quase sempre progressivos, que normalmente não tendem a se estabilizar a curto prazo. 
Embora pareça simples, a obtenção de diferencial de peso à desmama, situado entre o mínimo econômico e o máximo genético, em bezerros que recebem suplemento no creep-feeding é dependente da interação de muitos fatores. O criador deve estar sempre atento à eficiência de conversão no ganho de peso adicional. Em geral, aumentando-se o nível de nutrição do bezerro, prejudica-se a conversão do suplemento, em peso adicional, pois se os bezerros estiverem ao pé de vacas boas produtoras de leite e pastando forragem de boa qualidade, já deverão estar ganhando próximo do seu potencial genético. Dessa forma, o suplemento não aumentará as taxas de ganho, e os bezerros substituirão a forragem, que deveriam ter ingerido, pelo suplemento. Caso isso aconteça e o ajuste da dieta seja inadequado, pode tornar-se praticamente impossível viabilizar o uso do creep-feeding, mesmo que seja necessário obter à desmama apenas $8 \%$ a mais em peso de bezerros.

\section{Conclusões}

A suplementação da dieta de bezerros lactentes deve ser feita com cuidado e critério, pois os melhores resultados da suplementação devem ocorrer quando os bezerros se encontram em níveis subótimos de nutrição (escassez de forragem de boa qualidade e/ ou reduzida oferta de leite pela vaca). Na prática, a decisão de suplementar ou não dependerá fundamentalmente do estado nutricional e do crescimento observado nos bezerros, assim como da condição corporal das matrizes.

Mesmo com marcantes diferenças nas fórmulas dos suplementos e provavelmente próximos do potencial genético dos animais, os sistemas de nutrição avaliados proporcionaram desempenhos semelhantes, fato que os credenciam para a utilização em programas de suplementação para bezerros lactentes (creepfeeding) no período das águas. A escolha entre cada sistema de ajuste deve obedecer às limitações financeiras impostas pelo custo final de cada ração.

\section{Literatura Citada}

AGRICULTURAL AND FOOD RESEARCH COUNCIL AFRC. Energy and protein requirements of ruminants. Wallingford: CAB International, 1993. 59p.

ASSOCIATION OF OFFICIAL ANALYTICAL CHEMISTS AOAC. Animal feed. In: Official methods of analysis. 16.ed. Washington, D.C.: 1995. v.1. p.1-30.

BANZATTO, D.A.; KRONKA, S.N. Experimentação agrícola. 2.ed., Jaboticabal: Fundação Universidade Estadual Paulista, 1992. $247 \mathrm{p}$

FOX, D.G.; SNIFFEN, C.J.; O’CONNOR J.D. et al. A Net Carbohydrate and Protein System for evaluating cattle diets. III - Cattle requirements and diet adequacy. Journal of Animal Science, v.70, p.3578-96, 1992.

JARRIGE, R. Alimentación de bovinos, bovinos y caprinos. Madri: Mundi-Prensa, 1990. 431p.

LUSBY, K.S. Creep feeding beef calves. Oklahoma: Oklahoma Cooperative Service, 1995.9p. (Circular, 848)

MARTIN, T.G.; LEMENAGER, R.P.; SRINIVASAN, G. et al. Creep feeding as a factor influencing performance of cows and calves. Journal of Animal Science, v.53, n.1, p.33-9, 1981.

PACOLA, L.J.; NASCIMENTO, J.; MOREIRA, H.A. Alimentação suplementar de bezerros zebus: influência sobre a idade dos machos ao abate e das fêmeas à primeira cobrição. Boletim de Indústria Animal, v.34, n.2, p.177-201, 1977.

PACOLA, L.J.; RAZOOK, A.G.; BONILHA NETO, L.M. et al. Suplementação de bezerros em cocho privativo. Boletim de Indústria Animal, v.46, n.2, p.167-75, 1989.

PACOLA, L.J.; RAZOOK, A.G.; BONILHA NETO, L.M. et al. Influência da suplementação em cocho privativo sobre o desempenho pós-desmama de bezerros Nelore. Boletim de Indústria Animal, v.48, n.1, p.13-18, 1991.

PACOLA, L.J.; RAZOOK, A.G.; FIGUEIREDO, L.A. Suplementação pré e pós-desmama de fêmeas zebuínas da raça Nelore. Boletim de Indústria Animal, v.50, n.2, p.35-41, 1993.

TAYLOR, R.E.; FIELD, T.G. Beef production and management decisions. 3.ed. New Jersey: Prentice Hall, 1999. 714 p. 